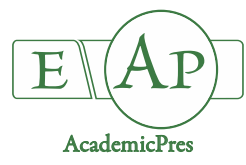

\title{
Shading Reduced the Injury Caused by Winter Chill on Pitaya Plant
}

\author{
Li WANG ${ }^{1,2}$, Xue ZHANG ${ }^{2}$, Weili $\mathrm{CHEN}^{1}$, Tujian XIAO ${ }^{2}$, \\ Xiaozhen $\mathrm{ZHAO}^{2}$, Yuhua $\mathrm{MA}^{2}$, Xuming $\mathrm{HUANG}^{1 *}$ \\ ${ }^{1}$ South China Agricultural University, College of Horticulture, Guangzhou, 510642, \\ China; lychee820427@163.com; cwl0521@foxmail.com; huangxm@scau.edu.cn (*corresponding author) \\ ${ }^{2}$ Guizhou Academy of Agricultural Sciences, Institute of Pomology Science, Guiyang, 550009, \\ China; zhangxuenl@126.com;116996580@qq.com;874247319@qq.com;m_yh79@163.com
}

\begin{abstract}
Pitaya (Hylocereus undatus Britton \& Rose) is widely cultivated in subtropical and tropical regions. Pitaya is cold-sensitive; most cultivars are injured during chilling winter periods, especially in subtropical regions. In this study, the effects of shading on the cold tolerance in pitaya plant were investigated. Pitaya plants were grown under full sunlight (control) or a shading net with a light blocking rate of about $60 \%$. Morphological and physiological performance of the overwintering pitaya plants were compared between the control and the shaded treatment. The results showed that shading treatment markedly reduced the chilling induced tissue necrosis. Contents of chlorophyll $a$, chlorophyll $b$, and total chlorophylls (chlorophyll $a+b$ ), the chlorophyll $a / b$ ratio, Fm and Fv/Fm were all higher in shading treatment than those in the control. Meanwhile, proline content and ascorbic acid peroxidase (APX) activity in the shading treatment were significantly increased, while malondialdehyde (MDA), the superoxide anion $\left(\mathrm{O}_{2}{ }^{-}\right)$and hydrogen peroxide $\left(\mathrm{H}_{2} \mathrm{O}_{2}\right)$ levels were significantly decreased by shading treatment. The results indicated that damage caused by chilling stress on pitaya was, at least partially, light-dependent; and in practical production, shading treatment can be used to reduce chilling injury in pitaya.
\end{abstract}

Keywords: antioxidant enzyme; chlorophyll; MDA; proline; ROS

\section{Introduction}

Hylocereus undatus, a large herbaceous fruit tree of the Hylocereus genus and the Cactaceae family, also known as red dragon fruit, lover fruit, fairy fruit, etc., are typical tropical fruits originated from Central America and naturally distributed in Costa Rica, Nicaragua, Mexico, Cuba and other countries (Nobel and Barrera, 2002). Therefore, the plant is sensitive to cold stress. When the temperature is below $4{ }^{\circ} \mathrm{C}$, pitaya plant will be seriously injured (Deng et al., 2014). Pitaya was introduced to Taiwan in the 1980s, and cultivation of pitaya in mainland China started in the late 1990s (Wang et al., 2011). In 2000, the plant was introduced to Guizhou province, and since then a small scale industry of pitaya has set up in Luodian County, in the basin along the Nanpan River, where a warm subtropical climate prevails with chilling winter. ' $\mathrm{Zi}$ Honglong' pitaya variety has been found to be suitable for local environment (Wang et al., 2004). Up till now, the planting area of pitaya in Guizhou has exceeded 6,666.7 ha, ranking the third in China. It has developed into a pillar industry in Guizhou karst mountain areas. However, local pitaya orchard suffered severe cold damage in winter in several years, which caused serious economic losses and restricted the development of pitaya industry in Guizhou (Denget al., 2011).

Although the promotion and cultivation of dragon fruit has made breakthroughs worldwide, the related physiological basic research is weak, especially in the study of physiological and biochemical mechanisms in response to cold and other stresses. Previous studies have shown that the interaction between low temperature and strong light is more harmful to plants than low temperature alone (Wang et al., 1986; Duan et al., 2003; Xu et al., 2013). However, there is no information about the performances of pitaya exposed to winter chill under different light exposures. This study tried to address the interplay of cold stress and light conditions in effect on pitaya, and evaluate the use of shading treatment to increase post-winter survival rate in Guizhou and other areas with similar winter conditions. 


\section{Materials and Methods}

\section{Materials}

The experiment was carried out in the demonstrative orchard of Pomology Institute, Guizhou Academy of Agricultural Sciences, located in Bacao Village, Zhenning County, Guizhou Province. The average temperature in January is $7.2{ }^{\circ} \mathrm{C}$, and the lowest $2{ }^{\circ} \mathrm{C}$. The experimental materials were three-year-old 'Zihonglong' pitaya plants, which were healthy and uniform in vigor, planted at a space of $2.0 \times 3.0 \mathrm{~m}$ under normal crop management.

\section{Methods}

On December $27^{\text {th }}, 2016$, three shading tunnels, set up as three experimental plots, were built with 20 meters wide and 30 meters long. 300 pitaya seedlings had been planted in each plot. The shading net covering the tunnel had a light transmittance of $40 \%$. During a sunny day, the noon light intensity reached $896.8 \pm 12.2 \mu \mathrm{mol}$ (photon) $\mathrm{m}^{-2} \mathrm{~s}^{-1}$. Under the shading tunnel, the noon light intensity was reduced to $410.1 \pm 15.3 \mu \mathrm{mol}$ (photon) $\mathrm{m}^{-2} \mathrm{~s}^{-1} .30$ days and 60 days after shading treatment (Foto 1 and 2), chilling injury on 100 marked plants each in the control and shaded treatment was observed and recorded. At the same time, chlorophyll realtime fluorescence values were measured using a PAM-2100 Portable Chlorophyll Fluorescence Analyzer (Walz, Effeltrich, Germany). The chlorophyll fluorescence parameters, such as minimum fluorescence (Fo), maximum fluorescence $(\mathrm{Fm})$, variable fluorescence $(\mathrm{Fv})$, and efficiency of primary conversion of light energy in PSIIs (Fv/Fm), were determined with an FMS-chlorophyll fluorescence meter (Hansatech, Britain) after 20 min dark adaptation with 10 replicates per treatment. At the same time, 5 mature branches $(n=5)$ each from shading treatment $(\mathrm{Sh})$ and the control (FS) were randomly taken, and brought back in an ice box to the laboratory to analyze the relevant

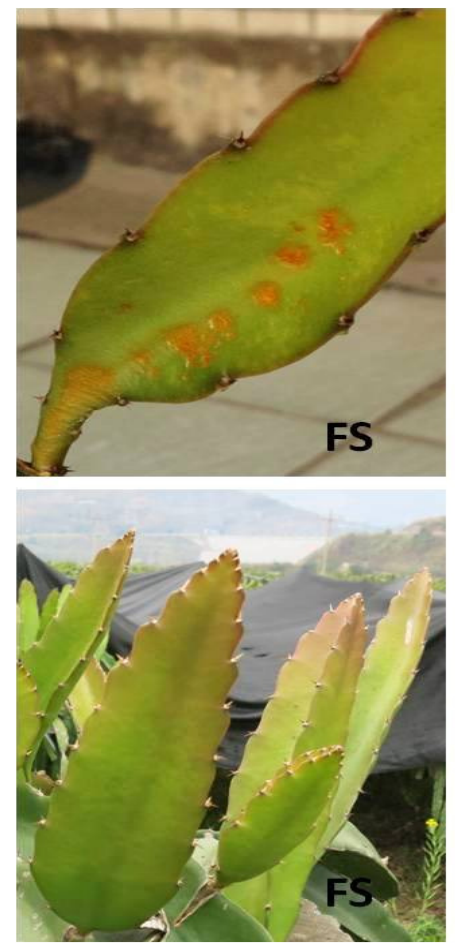

physiological indexes.

\section{Determination of chlorophyll contents}

Chlorophyll contents were measured according to Zheng (2006). $0.2 \mathrm{~g}$ of fleshy stem was weighed, and $20 \mathrm{ml}$ of acetone: absolute ethanol ( $\mathrm{V}: \mathrm{V}=1: 1)$ mixed extract was added, extracting for more than $12 \mathrm{~h}$. Then the absorbances of the resulting supernatant were taken at 649 and $665 \mathrm{~nm}$ using a spectrophotometer (Model DU730). The chlorophyll contents were calculated using the following equations:

$\mathrm{Chl} a\left(\mathrm{mg} \mathrm{g}^{-1}\right)=\left(13.95 \mathrm{~A}_{665}-6.88 \mathrm{~A}_{649}\right) \times \mathrm{V} / \mathrm{M}$

$\mathrm{Chl} b\left(\mathrm{mg} \mathrm{g}^{-1}\right)=\left(24.96 \mathrm{~A}_{649}-7.32 \mathrm{~A}_{665}\right) \times \mathrm{V} / \mathrm{M}$

Total Chl $\left(\mathrm{mgg}^{-1}\right)=\mathrm{Chl} a+\mathrm{Chl} b$

$\mathrm{V}$ : extract volume, $\mathrm{M}$ : sample weight.

\section{Determination of antioxidant enzymes}

The extraction of superoxide dismutase(SOD), Catalase (CAT), peroxidase (POD) and ascorbic acid peroxidase (APX) enzymes was modified based on Wutipraditkul et al. (2015). $0.3 \mathrm{~g}$ stem tissue was grinded into powder in liquid nitrogen, to which $1.7 \mathrm{~mL}$ cold extracting buffer $(0.1 \mathrm{M}$ phosphate buffer, pH 7.5, 0.5 mM EDTA, 5mM DTT, 0.1\% $(\mathrm{m} / \mathrm{v})$ protease inhibitor) was added. The mixture was centrifuged at $10000 \mathrm{~g}$ and $4^{\circ} \mathrm{C}$ for $20 \mathrm{~min}$. The supernatant was collected as the crude enzyme extract. Total SOD activity was assayed by monitoring the inhibition of nitroblue tetrazolium photochemical reduction (NBT). One unit of SOD activity was defined as the amount of enzyme required to cause $50 \%$ inhibition of the reduction rate of NBT monitored at $560 \mathrm{~nm}$. APX activity was measured following the oxidation of ascorbic acid (ASC) at $290 \mathrm{~nm}$ for $1 \mathrm{~min}$. POD activity was determined specifically with guaiacol at $436 \mathrm{~nm}$, and the activities of CAT were measured by the determination of the rate constant of hydrogen peroxide decomposition.

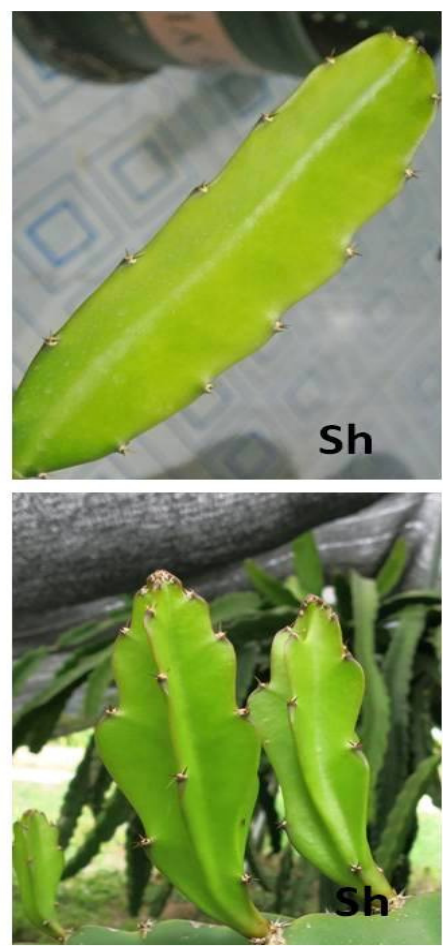

Foto 1. Plant appearance at 30 days of treatment; FS indicates full sunlight and Sh 60\% shading 
472
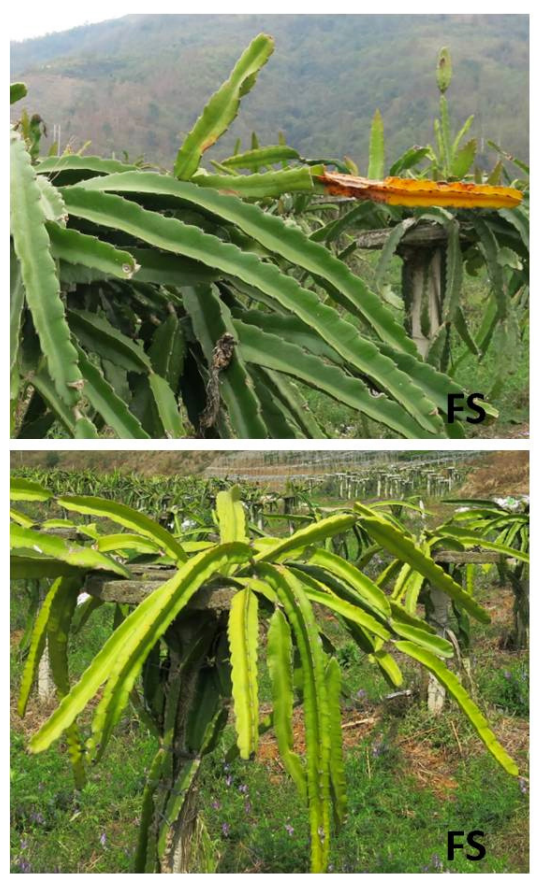

Foto 2. Plant appearance at 60 days of treatment; FS indicates full sunlight and Sh $60 \%$ shading

Determination of proline and malondialdehyde (MDA) content

Proline contents were measured according to Bates et al. (1973). $0.5 \mathrm{~g}$ stem tissue was homogenized in $5 \mathrm{~mL}$ of $3 \%$ aqueous sulfosalicyclic acid and centrifuged $(12,000 \mathrm{rpm}, 15$ min, $\left.4{ }^{\circ} \mathrm{C}\right)$. The mixture of supernatant $(2 \mathrm{~mL})$, acidninhydrin $(2 \mathrm{~mL})$ and glacial acetic acid $(2 \mathrm{~mL})$ was incubated at $100{ }^{\circ} \mathrm{C}$ for $45 \mathrm{~min}$ and then extracted with toluene. The absorbance of toluene was measured at 520 $\mathrm{nm}$. The amount of proline was calculated from the standardized proline curve.

MDA (Methane Dicarboxylic Aldehyde) content according to Karabal et al. (2003) with some modifications. $0.5 \mathrm{~g}$ stem tissue were collected from each treatment and cut into small pieces and homogenized by in $5 \mathrm{~mL}$ of $5 \%$ trichloroacetic acid (TCA) in ice bath. The homogenates were centrifuged at $10,000 \times \mathrm{g}$ for $10 \mathrm{~min} ; 1 \mathrm{~mL}$ of the supernatant was added with $4 \mathrm{~mL}$ of $20 \%$ TCA containing $0.5 \%$ thiobarbituric acid. The resulting mixture was incubated at $98{ }^{\circ} \mathrm{C}$ for $40 \mathrm{~min}$, then cooled to room temperature and centrifuged at $10,000 \times \mathrm{g}$ for $5 \mathrm{~min}$. The supernatant was subjected to analysis with a spectrophotometer. The MDA content was calculated at A450, A532 and A600 using coefficient of absorbance of $155 \mathrm{mM}^{-1} \mathrm{~cm}^{-1}$.

Determination of reactive oxygen species (ROS)

As two major indicators of ROS accumulation,
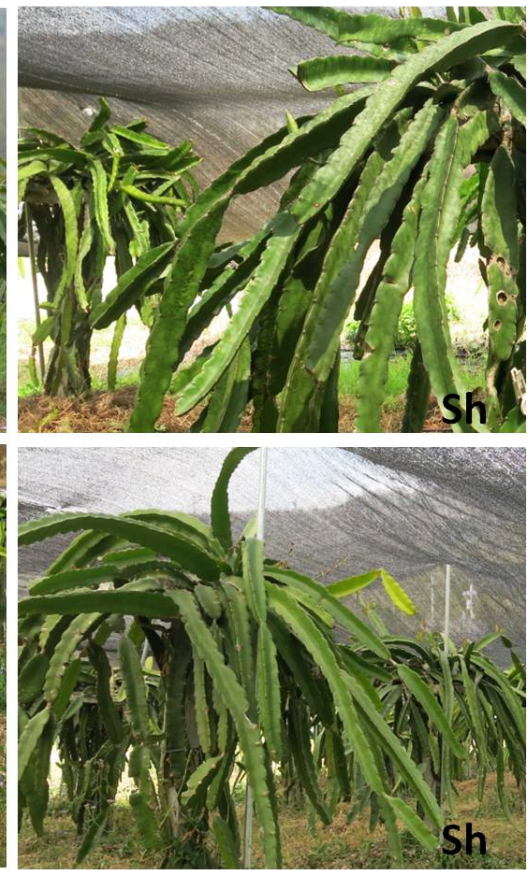

hydrogen peroxide $\left(\mathrm{H}_{2} \mathrm{O}_{2}\right)$ and superoxide radical $\left(\mathrm{O}_{2}^{-}\right)$ contents were quantified using the titanium sulphate method and the Plant $\mathrm{O}_{2}-$ ELISA Kit (10-40-488, Bejing Dingguo, Beijing, China), respectively, as previously described (Shi et al., 2013, 2014).

\section{Data analysis}

Data were processed by using Microsoft Excel 2007 and graph generation were done with Origin 6.0. LSD multiple range tests and $\mathrm{t}$-tests were conducted with software DPS v7.05.

\section{Results}

Effect of shading on pitaya morphology at low temperature in winter

In Table 1 , at 30 days of shading treatment, $2 \%$ plants in shading treatment showed chlorosis in the stem, while under full sun, $12 \%$ plants had chlorosis. At the same time, there was no difference in yellow spots between the two treatments. At 60 days of shading, $6 \%$ and $5 \%$ of the shaded plants had chlorosis and yellow spots in the stem, respectively, while the full sun group had $56 \%$ and $24 \%$, respectively. In addition, $2 \%$ of plants under full sun displayed necrosis or death, which was not found in the shaded plants. The results showed that shading treatment significantly improved the cold tolerance of the pitaya plant.

Table 1. The effect of shading on incidence of chilling injury symptoms in pitaya plants

\begin{tabular}{|c|c|c|c|c|c|}
\hline Days of treatment & Temperature $\left({ }^{\circ} \mathrm{C}\right)$ & Humidity (\%) & Chilling injury symptom & FS & Sh \\
\hline \multirow{2}{*}{30} & \multirow{2}{*}{7.1} & \multirow{2}{*}{87.8} & Chlorosis & $12 \% \pm 2.31 \mathrm{a}$ & $2 \% \pm 0.22 b$ \\
\hline & & & Yellow spot & $4 \% \pm 2.92 \mathrm{a}$ & $1 \% \pm 0.47 a$ \\
\hline \multirow{3}{*}{60} & \multirow{3}{*}{16.2} & \multirow{3}{*}{89.3} & Chlorosis & $56 \% \pm 7.64 a$ & $6 \% \pm 1.31 \mathrm{~b}$ \\
\hline & & & Yellow spot & $24 \% \pm 3.42 \mathrm{a}$ & $5 \% \pm 0.95 b$ \\
\hline & & & Necrosis rate & $2 \% \pm 0.31 \mathrm{a}$ & $0 \mathrm{~b}$ \\
\hline
\end{tabular}

Note: FS indicates full sunlight and $\mathrm{Sh} 60 \%$ shading; Different letters indicated significance at $\mathrm{P} \leq 0.05$ ( $\mathrm{t}$ test) between different times and treatments. 
Effects of shading on chlorophyll components in pitaya stem

From the field observation, the color of pitaya stems under the shading treatment was obviously dark green, while that in in full sun treatment was yellowish green. At 30 days of shading treatment, the contents of chlorophyll $b$ and total chlorophylls (chlorophyll $a+b$ ) in shading treatment were slightly lower than those in the full sun treatment, while the chlorophyll $a$ and chlorophyll $a / b$ were significantly higher under shade (Table 2). At 60 days of shading treatment, there was a significant difference in chlorophyll content in pitaya stem between the treatments. The chlorophyll content in full sun treatment was significantly lower compared to that at 30 days of treatment, while in the shading treatment the chlorophyll content increased with time. Moreover, contents of chlorophyll $a$, chlorophyll $b$, total chlorophylls (chlorophyll $a+b$ ) and chlorophyll $a / b$ ratio at day 60 day were all significantly increased by the shading treatment.

\section{Effect of shading on chlorophyll fluorescence}

At 30 days of shading treatment, Fo and Fm values of the shading treatment were significantly higher than that in full sun, and there was no difference in the Fv/Fm ratio (Table 3). By 60 days of shading treatment, the Fo values of the full sunlight and shading treatments had been increased at different degrees. The $\mathrm{Fv} / \mathrm{Fm}$ ratio did not change significantly after shading, but that in the full sun treatment decreased significantly. The difference in Fo value between the control and the treatment was not significant, while the Fm value and $\mathrm{Fv} / \mathrm{Fm}$ ratio were significantly higher in the shading treatment.

Effects of shading on the contents of proline (Pro) and MDA in pitaya stem

At 30 days of shading treatment, Pro content was 37.28

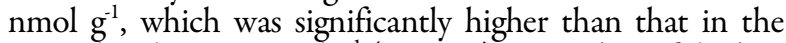
control with $20.09 \mathrm{nmol} \mathrm{g}^{-1}$ (Fig.1. A). At 60 days of shading treatment, the same pattern was found. Pro content in the shading treatment was $110.32 \mathrm{nmol} \mathrm{g}^{-1}$, still significantly higher than that in in the control $\left(48.73 \mathrm{nmol} \mathrm{g}^{-1}\right)$ (Fig.1. A). It can be seen that the content of Pro in the treatment and the control increased significantly with time of exposure to winter chill.
At 30 days of shading treatment, there was no significantly difference in MDA content between the shading treatment $\left(1.33 \mu \mathrm{mol} \mathrm{g}^{-1}\right)$ and the control $(1.45 \mu \mathrm{mol}$ $\mathrm{g}^{-1}$ ). At 60 days of shading treatment, MDA content in the shading treatment showed a slightly increase (to $1.71 \mu \mathrm{mol} \mathrm{g}$ $\left.{ }^{1}\right)$ with no significant difference compared with that at day 30. However, the MDA content in the control increased

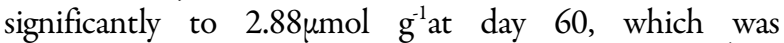
significantly higher than that in the shading treatment (Fig. 1.B).

\section{Effect of shading on ROS}

After 30 days of shading treatment, the superoxide anion $\left(\mathrm{O}_{2-}^{-}\right)$content was $20.03 \mu \mathrm{mol} \mathrm{g}{ }^{-1}$, slightly lower than that in the control $\left(23.56 \mu \mathrm{mol} \mathrm{g}^{-1}\right)$. By 60 days of shading treatment, the $\mathrm{O}_{2}-$ content in the full sun treatment had increased sharply to $28.06 \mu \mathrm{mol} \mathrm{g}^{-1}$, while a slight increase was found in the shading treatment (Fig. 2. A), and the $\mathrm{O}_{2}$ content in the shading treatment was significantly lower than that in control at day 60.

Changes in hydrogen peroxide $\left(\mathrm{H}_{2} \mathrm{O}_{2}\right)$ are shown in Fig. 2. B. There was no significant difference in $\mathrm{H}_{2} \mathrm{O}_{2}$ content between the shading treatment and the control at day 30 . At 60 days of treatment, the $\mathrm{H}_{2} \mathrm{O}_{2}$ content in the full sun control increased sharply, while in the shading treatment there was no significant change, and $\mathrm{H}_{2} \mathrm{O}_{2}$ in the control was significantly higher than in the shading treatment.

\section{Effect of shading on antioxidant enzyme activities}

As shown in Fig. 3. A, at 30 days of shading treatment, SOD activity in the shading treatment was $109.1 \mathrm{U} \mathrm{g}^{-1}$, while that in the control was $148.21 \mathrm{U} \mathrm{g}^{-1}$ with no significant difference. By 60 days treatment, SOD activity in both the shading treatment $\left(138.04 \mathrm{U} \mathrm{g}^{-1}\right)$ and the control $\left(189.34 \mathrm{U} \mathrm{g}^{-1}\right)$ had increased, but the difference between treatments was still not significant.

APX activity in the shading treatment was $2.15 \mu \mathrm{mol}$ $\min ^{-1} \mathrm{~g}^{-1}$, significantly higher than that in the control (1.35 $\mu \mathrm{mol} \min ^{-1} \mathrm{~g}^{-1}$ ) (Fig. 3B). APX activity in both shading treatment $\left(3.57 \mu \mathrm{mol} \mathrm{min}^{-1} \mathrm{~g}^{-1}\right)$ and control $(2.25 \mu \mathrm{mol} \mathrm{min}$ $\left.{ }^{1} \mathrm{~g}^{-1}\right)$ showed an increased pattern. At 60 days of treatment, APX activity in shading treatment was still significantly higher.

Table 2. Effect of shading on the content of chlorophyll components in pitaya stem

\begin{tabular}{cccccc}
\hline $\begin{array}{c}\text { Days of } \\
\text { treatment }\end{array}$ & Treatment & $\begin{array}{c}\text { Chlorophyll } a \\
\left(\mathrm{mg} \mathrm{g}^{-1} \mathrm{FW}\right)\end{array}$ & $\begin{array}{c}\text { Chlorophyll } b \\
\left(\mathrm{mg} \mathrm{g}^{-1} \mathrm{FW}\right)\end{array}$ & $\begin{array}{c}\text { Chlorophyll }(a+b) \\
\left(\mathrm{mg} \mathrm{g}^{-1} \mathrm{FW}\right)\end{array}$ & Chlorophyll $(a / b)$ \\
\hline \multirow{2}{*}{30} & $\mathrm{FS}$ & $1.17 \pm 0.08 \mathrm{~b}$ & $0.37 \pm 0.03 \mathrm{a}$ & $1.55 \pm 0.10 \mathrm{a}$ & $3.15 \pm 0.12 \mathrm{c}$ \\
& Sh & $1.21 \pm 0.05 \mathrm{a}$ & $0.32 \pm 0.07 \mathrm{a}$ & $1.54 \pm 0.11 \mathrm{a}$ & $3.69 \pm 0.07 \mathrm{~b}$ \\
\hline \multirow{2}{*}{60} & FS & $0.91 \pm 0.18 \mathrm{c}$ & $0.27 \pm 0.08 \mathrm{~b}$ & $1.18 \pm 0.17 \mathrm{~b}$ & $3.30 \pm 0.14 \mathrm{c}$ \\
& Sh & $1.30 \pm 0.07 \mathrm{a}$ & $0.34 \pm 0.05 \mathrm{a}$ & $1.64 \pm 0.08 \mathrm{a}$ & $3.86 \pm 0.09 \mathrm{a}$ \\
\hline
\end{tabular}

Note: FS indicates full sunlight and Sh 60\% shading, FW indicates fresh weight; Different letters indicated significance at P $\leq 0.05$ (LSD test) between different times and treatments.

Table 3. Effects of shading on chlorophyll fluorescence parameters of pitaya stem

\begin{tabular}{ccccc}
\hline Days of treatment & Treatment & Fo & Fm & Fv/Fm \\
\hline \multirow{2}{*}{30} & FS & $37.45 \pm 5.17 \mathrm{c}$ & $205.18 \pm 18.23 \mathrm{c}$ & $0.82 \pm 0.06 \mathrm{ab}$ \\
& Sh & $62.00 \pm 9.22 \mathrm{~b}$ & $482.72 \pm 22.01 \mathrm{~b}$ & $0.87 \pm 0.03 \mathrm{a}$ \\
\hline \multirow{2}{*}{60} & FS & $78.83 \pm 8.25 \mathrm{a}$ & $400.33 \pm 20.36 \mathrm{~b}$ & $0.79 \pm 0.02 \mathrm{~b}$ \\
& Sh & $81.17 \pm 5.14 \mathrm{a}$ & $708.66 \pm 40.17 \mathrm{a}$
\end{tabular}

Note: FS indicates full sunlight and Sh $60 \%$ shading; Different letters indicated significance at $\mathrm{P} \leq 0.05$ (LSD test) between different times and treatments. 

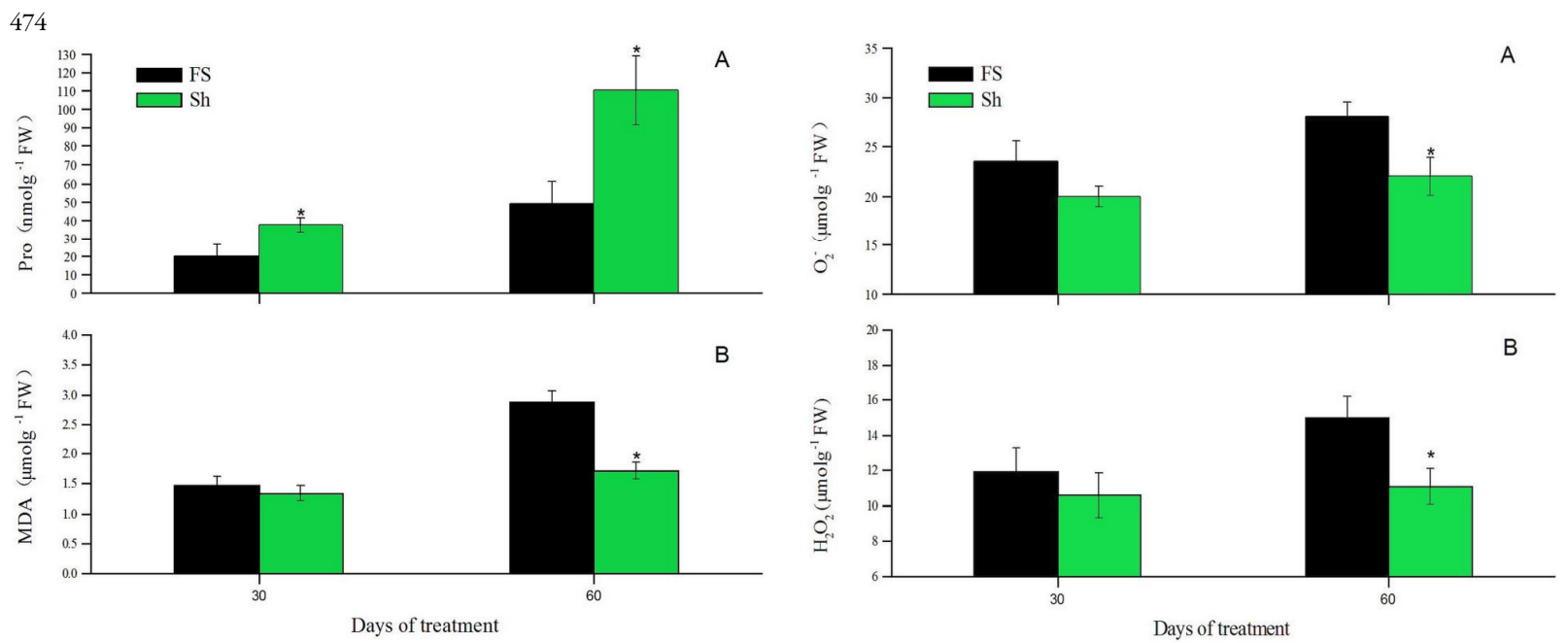

Fig. 1. Effects of shading on the contents of Pro and MDA in pitaya stem. Note: Fig. 1. A and B indicate contents of Pro and MDA, respectively; ' ${ }^{*}$ ' indicate significant difference at $\mathrm{P} \leq 0.05$ ( $t$ test) between the control (FS) and the treatment (Sh), FS indicates full sunlight and Sh 60\% shading, FW indicates fresh weight

Fig. 2. Effect of shading ROS content in pitaya stem. Note: Fig. 2. $\mathrm{A}$ and $\mathrm{B}$ indicate contents of $\mathrm{O}_{2}{ }^{-{ }^{-}}$and $\mathrm{H}_{2} \mathrm{O}_{2}$, respectively; '*' indicate significant difference at $\mathrm{P} \leq 0.05$ ( $\mathrm{t}$ test) between the control (FS) and the treatment (Sh), FS indicates full sunlight and Sh $60 \%$ shading, FW indicates fresh weight

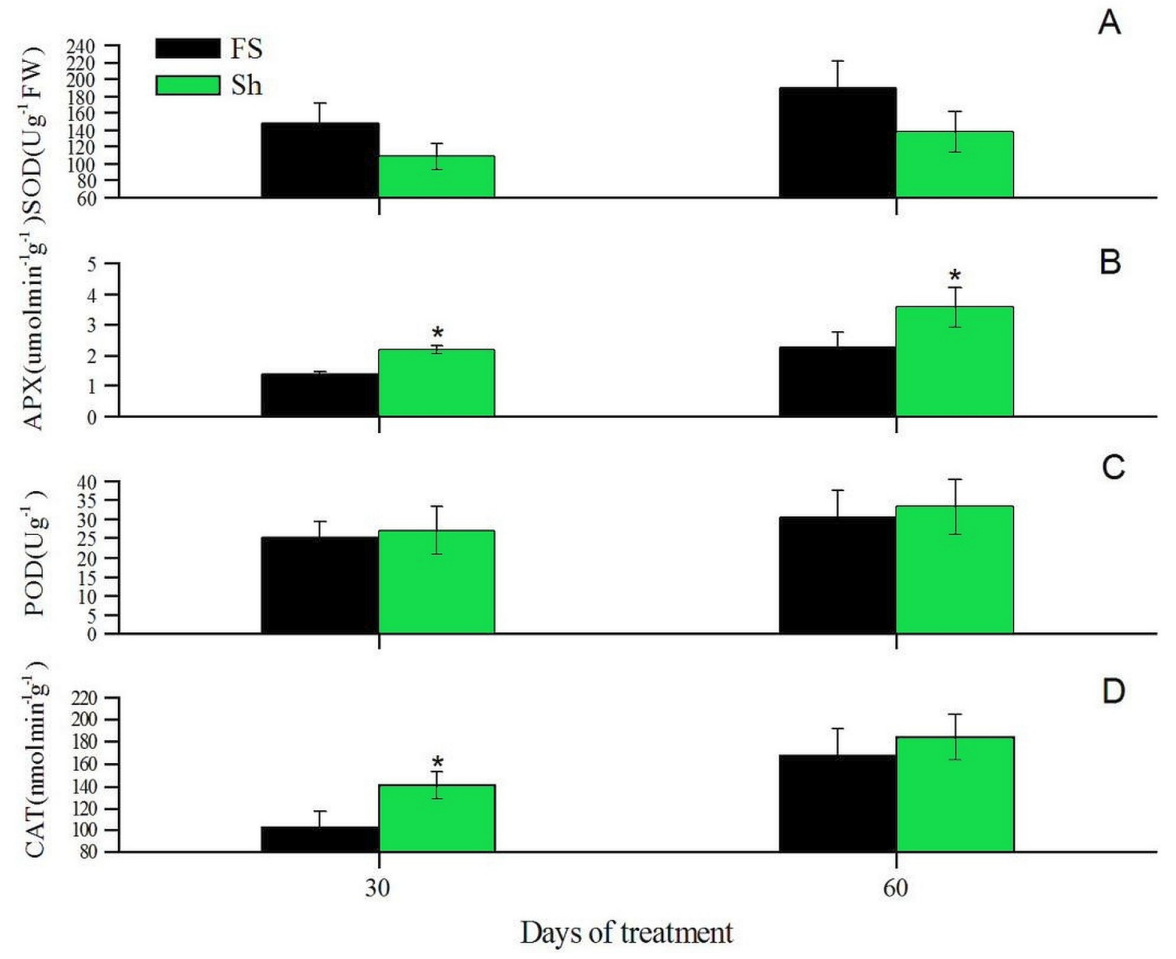

Fig. 3. Effect of shading on the activities of antioxidant enzymes in pitaya stem. Note: Fig. 3. A, B, C and D indicate SOD, APX, POD and CAT activity, respectively; '*' indicate significant difference at $\mathrm{P} \leq 0.05$ ( $\mathrm{t}$ test) between the control (FS) and the treatment (Sh), FS indicates full sunlight and Sh 60\% shading, FW indicates fresh weight

As shown in Fig. 3. C, the POD enzyme activity in the shading and full sun treatment was very low, and there was no difference between time and treatments.

CAT activity in the shading and full sunlight was also low. At 30 days of shading treatment, CAT activity in the shading treatment and the control was 140.82 and 102.68 nmol $\min ^{-1} \mathrm{~g}^{-1}$, respectively (Fig. $3 \mathrm{D}$ ). And the shading treatment was significantly higher than the full sun treatment. By 60 days of shading treatment, CAT activity in the treatment $\left(184.32 \mathrm{nmol} \mathrm{min}{ }^{-1} \mathrm{~g}^{-1}\right)$ and control (168.36 nmol $\left.\min ^{-1} \mathrm{~g}^{-1}\right)$ had increased, but there was no significant difference between treatments. 


\section{Discussion}

Our study showed that pitaya showed various chilling injury symptoms under natural winter conditions, including chlorosis, yellow spots and necrosis. Development of chlorosis and yellow spots are the early symptoms of chilling injury. The chlorophyll content reflects the growth of the plant and the photosynthetic capacity of the leaves to a large extent, which is also related to the photosynthetic rate and photosynthetic intensity of the leaves. Low temperature often causes damage to the morphological structure and function of chloroplasts. When plants are subjected to low temperature, the reaction center of PSII is inhibited, together with blocked electron transfer and reduced photosynthetic function (Sun et al., 2016). The structure and function of plant leaves are not only determined by genetic background, but also by the environment factors, among which light is of great importance (Monneveux et al., 2003). Wang et al. (1986) reported that low temperature in the light was more likely to cause cold damage to plants than that in dark conditions. Studies have found that highintensity shading can reduce $\mathrm{P}_{\mathrm{N}}$ value in plant leaves (Mu $e t$ al., 2010), while low-intensity shading increases it and promotes the growth of wheat ( $\mathrm{Li}$ et al., 2010). At low temperatures, the increase of photosynthetic pigment content is an adaptive response so as to capture as much light as possible and enhance light utilization (Shaver et al., 2008). Changes in light intensity also cause the alteration of chloroplast structure and chlorophyll components (Evans and Poorter, 2010). After shading treatment, the total chlorophyll content in winter wheat leaves increased, while Chl $b$ increased faster than $\mathrm{Chl} a$ content, causing the decrease of Chl $a / b$ (Xu et al., 2013). In our study, shading increased chlorophylls in pitaya stem, which was similar to the response reported in wheat, but our data showed an increase in chlorophyll $a / b$ ratio by shading, opposite to the result obtained in wheat (Xu et al., 2013). We also found that, under cold condition with full sunlight, pitaya tended to lose some chlorophylls, while under shade, chlorophyll displayed an increase pattern. Therefore, chlorophyll metabolism underwent dramatic changes under different light conditions.

Light or shade regimes were considered to affect not only photosynthetic rate, but also chlorophyll fluorescence. Exposure to excess irradiance can lead to photoinhibition, which is characterized by a light-dependent reduction in the fundamental quantum yield of photosynthesis and a loss of photosystem II (PSII) activity (Osmond, 1994). Fo and Fm refer to the fluorescence yield of the Photosystem II (PSII) reaction center when it is fully open and completely closed, respectively. Fv/Fm value is the maximum photochemical quantum yield of PSII, which is commonly used to measure the efficiency of primary conversion of light energy in PSII. A reduction in $\mathrm{Fv} / \mathrm{Fm}$ can be used as an indication of photoinhibition (Robakowski, 2005). Soitamo et al. (2008) reported that about $10 \%$ decrease in the photochemical efficiency $(\mathrm{Fv} / \mathrm{Fm})$ and the oxygen evolving activity of photosystem II (PSII) was measured after cold and light treatment. In this study, Fo and Fm values of the shading treatment were significantly higher than those in the control, which agrees with a higher concentration in chlorophyll a in the shading treatment. At 30 days of treatment, there was no difference in the $\mathrm{Fv} / \mathrm{Fm}$ ratio between the treatments. However, full sun exposure and cold conditions caused significant reduction in $\mathrm{Fv} / \mathrm{Fm}$, reflecting severe photoinhibiton or photo-damage had occurred, while under shade, Fv/Fm value maintained high. The result suggested that chilling injury under full sun involves photo-damage, and shading treatment effectively reduced this damage.

Studies have suggested that low winter temperatures inhibit carbon assimilation but do not affect photon capture (Hughes et al., 2012), leading to an imbalance between light absorption and processing (Verhoeven, 2014). This imbalance ultimately results in the production of reactive oxygen species (ROS), which can cause membrane lipid peroxidation damage, and the increase of MDA content (Ashraf and Ali, 2008; Yang et al., 2007). ROS include free radicals such as superoxide radical $\left(\mathrm{O}_{2}^{-}\right)$and hydrogen peroxide $\left(\mathrm{H}_{2} \mathrm{O}_{2}\right)$ (Cavatte et al., 2012). Within a certain range, plant's own antioxidant system maintains a dynamic balance between free radical production and clearance, reactive oxygen levels remain low and do no damage to cells (Hashempour et al., 2014). The occurrence of photodamage may be related to the production of reactive oxygen species in the chloroplast, and the improvement of the capacity of active oxygen scavenging contributes to the prevention of photoinhibition damage to a certain extent. When the generation of ROS in cells exceeds the ability of organism to remove them, the accumulation of ROS will cause a variety of harmful cytological effects, leading to metabolic dysfunction in cells, lipid peroxidation and so on (Ge et al., 2006). Our study showed chilling and full sunlight caused chlorosis and tissue necrosis with significant accumulation of $\mathrm{H}_{2} \mathrm{O}_{2}$. These symptoms were consequences of ROS action. ROS attack lipid bilayers in the membrane with accumulation of lipid peroxidation product, MDA. The higher MDA concentration found in the full sunlight treatment indicated severer damage caused by ROS. In the long process of evolution, various effective ROS removal mechanisms and protective systems (enzymatic or nonenzymatic) have been formed to mitigate the direct damage caused by ROS to plants (Zushi et al., 2009). Catalase (CAT), superoxide dismutase (SOD), peroxidase (POD) and ascorbic acid peroxidase (APX) in enzymatic system are the main scavenging enzymes in the study of reactive oxygen scavenging system of plants under the abiotic stress. SOD is involved in the detoxification of $\mathrm{O}_{2}$, however, leading to the formation of $\mathrm{H}_{2} \mathrm{O}_{2}$, which is removed by CAT (Jiménez et al., 1997). Previous studies have shown that under the mixed treatment of low temperature and strong light, the activities of SOD and APX in spinach increased (Schöner and Krause, 1990), and when transferring from low light to high light, the activities of SOD and CAT enzymes in leaves also increased (Mishra et al., 2010). Recent studies in winter wheat pointed out that under $22 \%$ shading, SOD, POD, and CAT activities increased, and MDA content decreased; while under $50 \%$ and $90 \%$ shading treatments, their activities reduced, while MDA content increased ( $\mathrm{Xu}$ et al., 2013). Activities of these antioxidant enzymes increase with development of stresses. In our study, we showed similar change pattern in pitaya stems with time of exposure to winter chill. However, under shade, the increase in 
476

antioxidant enzyme activities was more prominent than under full sunlight. Hence, shading treatment induced a higher capacity in ROS scavenging.

Low temperatures also cause plants to accumulate osmotic regulatory substances (such as proline etc.), which can not only improve the water-retaining ability of cells, but also protect plants from damage (Xu and Chen, 2008). In our study, the proline (Pro) content in the shading treatment was higher than in the full sunlight control, suggesting shading induced a stronger osmotic adjustment.

\section{Conclusions}

Under low temperature conditions in winter, the response of pitaya plant to chilling stress under shading and full sunlight was different. Compared to plants under full sun, shaded pitaya plant had a better performance under winter chill, as reflected by lighter symptom of chilling injury, higher contents of chlorophylls and $\mathrm{Fv} / \mathrm{Fm}$ value, and less accumulation of ROS. Hence shading increases chilling-tolerance in pitaya. This effect of shading may involve multiple mechanisms including reduced photodamage, better ROS scavenging system and higher accumulation of protective osmoregulants such as proline.

\section{Acknowledgements}

This study was supported by the National Natural Science Foundation of China (No.31560543) and Guizhou Talent project ([2017]5603), and Guangdong Elite Fruits Industry Technology System (2017LM1130).

\section{References}

Ashraf M, Ali Q (2008). Relative membrane permeability and activities of some antioxidant enzymes as the key determinants of salt tolerance in canola (Brassica napus L.). Environmental and Experimental Botany 63:266-273.

Bates L, Waldren R, Teare I (1973). Rapid determination of free proline for water-stress studies. Plant Soil 39:205-207.

Zheng BS (2006). Modern Plant Physiology and Biochemistry Research Technology, China Meteorological Press.

Cavatte PC, Martins SCV, Morais LE, Silva PEM, DaMatta FM (2012). The physiology of abiotic stresses. Plant Breeding for Abiotic Stress Tolerance. Springer-Verlag, Berlin Heidelberg, pp 21-51.

Deng RJ, Fan JX, Cai YQ (2011). Present research status and industrial development of pitaya at home and abroad. Guizhou Agricultural Sciences 39(6):188-192.

DengRJ, Fan JX, Wang YQ, Jin JF,Liu T(2014). Semilethal temperature of Pitaya under low temperature stress and evaluation on their cold resistance. Zhiwu Shengi Xuebao (Plant Physiology Journal) 50(11):1742-1748.

Duan W,LiXG, MengQW,Zhao SJ (2003). Photoinhibiton mechanisms of plant under low temperature. Acta Botanica Boreali-Occidentalia Sinica23(6):1017-1023.

Evans JR, Poorter H (2010). Photosynthetic acclimation of plants to growth irradiance: the relative importance of specific leaf area and nitrogen partitioning in maximizing carbon gain. Plant Cell and Environment
24(8):755-767.

Ge TD, Sui FG, Bai LP, Lu YY,Zhou GS (2006). Effects of water stress on the protective enzyme activities and lipid peroxidation in roots and leaves of summer maize. Agricultural Sciences in China 5(4):291-298.

Hashempour A, Ghasemnezhad M, Ghazvini RF, Sohani MM (2014). Olive (Olea europaea L.) freezing tolerance related to antioxidant enzymes activity during cold acclimation and non-acclimation. Acta Physiologiae Plantarum 36(12):3231-3241.

Hughes NM, Burkey KO, Cavender-Bares J, Smith WK (2012). Xanthophyll cycle pigment and antioxidant profiles of winter-red (anthocyanic) and winter-green (acyanic) angiosperm evergreen species. Journal of Experimental Botany 63:1895-1905.

Jiménez A, Hernandez JA, Del Río LA, Sevilla F (1997). Evidence for the presence of the ascorbate-glutathione cycle in mitochondria and peroxisomes of pea leaves. Plant Physiology 114:275-284.

Karabal E, Yucel M, Oktem HA (2003). Antioxidant responses of tolerant and sensitive barley cultivars to boron toxicity. Plant Science 164:925933.

Li HW, Dong J, Wollenweber B, Dai TB, Cao WX (2010). Effects of shading on morphology, physiology and grain yield of winter wheat. European Journal of Agronomy 33(4):267-275.

Mishra NP, Fatma T, Singhal GS (2010). Development of antioxidative defense system of wheat seedlings in response to high light. Physiologia Plantarum 95(1):77-82.

Monneveux P, Pastenes C, Reynolds MP (2003). Limitations to photosynthesis under light and heat stress in three high-yielding wheat genotypes. Journal of Plant Physiology 160:657-666.

Mu H, Jiang D, Wollenweber B, Dai T, Jing Q, Cao W (2010). Long-term low radiation decreases leaf photosynthesis, photochemical efficiency and grain yield in winter wheat. Journal of Agronomy and Crop Science 196:38-47.

Nobel PS, Barrera EDL (2002). Stem water relations and net $\mathrm{CO}_{2}$ uptake for a hemiepiphytic cactus during short-term drought. Environmental and Experimental Botany 48(2):129-137.

Osmond CB (1994). What is photoinhibition? Some insights from comparisons of shade and sun plants. In: Baker NR, Bowyer JR (Eds). Photoinhibition of photosynthesis: molecular mechanisms to the field. Bios Scientific, Oxford pp 1-24.

Robakowski P (2005). Susceptibility to low-temperature photoinhibition in three conifers differing in successional status. Tree Physiology 25(9):1151-1160.

Schöner S, Heinrich KG (1990). Protective systems against active oxygen species in spinach: response to cold acclimation in excess light. Planta 180(3):383-389.

Shaver JM, Oldenburg DJ, Bendich AJ (2008). The structure of chloroplast DNA molecules and the effects of light on the amount of chloroplast DNA during development in Medicago truncatula. Plant Physiology 146(3):1064-1074.

Shi H, Ye T, Chan Z (2014). Nitric oxide-activated hydrogen sulfide is essential for cadmium stress response in bermudagrass (Cynodon dactylon (L).Pers.).Plant Physiology and Biochemistry 74(136):99-107.

Shi H, Ye T, Chan Z (2013). Exogenous application of hydrogen sulfide donor sodium hydrosulfide enhanced multiple abiotic stress tolerance in 
bermudagrass (Cynodon dactylon (L). Pers.). Plant Physiology and Biochemistry 71:226-234.

Soitamo AJ, Piippo M, Allahverdiyeva Y, Battchikova N, Aro EM (2008). Light has a specific role in modulating Arabidopsis gene expression at low temperature. BMC Plant Biology 8:13.

Sun DZ, Han XR, Peng J, Fan F (2016). The effect of exogenous salicylic acid on PSII photochemical efficiency and distribution and utilization of luminous energy in tomato seedlings. Acta Horticulturae Sinica 43(8):1482-1492.

Verhoeven A (2014). Sustained energy dissipation in winter evergreens. New Phytologist 201:57-65.

Wang B,Zheng W (2004). The development prospect of dragon fruit in the south subtropical region of Guizhou. Fujian Fruits 1(128):36-38.

Wang X, Xiang QY, Tan W, Cai YQ, Fan JX, Deng RJ (2011). The climatic division of pitaya in Guizhou province based on RS and GIS. Guizhou Agricultural Sciences 39(3):229-233.

Wang YR, Liu HX, Li P, Zeng SX, Zhen LP, GuoJY (1986). Effects of low temperature on membrane lipid peroxidation in photosynthetic organs of rice seedlings under light and dark conditions. Plant Physiology Communications 12(3):244251.
Wutipraditkul N, Wongwean P, Buaboocha T (2015). Alleviation of saltinduced oxidative stress in rice seedlings by proline and/or gycinebetaine. Biologia Plantarum 59(3):547-553.

Xu C, Yin YP, Cai R, Wang P, Ni YL, Guo JX, Chen EY, Cui ZY, Liu T, Yang DQ, Wang ZL (2013). Responses of photosynthetic characteristics and antioxidative metabolism in winter wheat to postanthesis shading. Photosynthetica 51(1):139-150.

Xu Y, Chen FD (2008). Cold semi lethal temperature and cold adaptability of 8 species of chrysanthemum. Journal of Horticulture 35(4):559-564.

Yang SH, Wang LJ, Li SH, Duan W, Loescher W, Liang ZC (2007). The effects of UV-B radiation on photosynthesis in relation to photosystem II photochemistry, thermal dissipation and antioxidant defenses in winter wheat (Triticum aestivum L.) seedlings at different growth temperatures. Functional Plant Biology 34:907-917.

Zushi K, Matsuzoe N, Kitano M (2009). Developmental and tissue specific changes in oxidative parameters and antioxidant systems in tomato fruits grown under salt stress. Scientia Horticulturae 122(3):362-368. 